\title{
P)

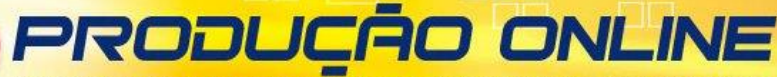

\section{O PROCESSO DE ENCURTAMENTO DE UMA CADEIA PRODUTIVA DE ARROZ: MOTIVADORES E IMPLICAÇÕES}

\section{THE SHORTENING PROCESS OF A RICE SUPPLY CHAIN: MOTIVATORS AND IMPLICATIONS}

\author{
Valquires Martins de Santana*E-mail: valquires@ifto.edu.br \\ Miguel Afonso Sellitto*E-mail: sellitto@unisinos.br \\ *Universidade do Vale do Rio dos Sinos (UNISINOS), São Leopoldo, RS
}

\begin{abstract}
Resumo: Esse estudo trata do encurtamento de uma cadeia produtiva de arroz, envolvendo a indústria de beneficiamento e os produtores do município de Lagoa da Confusão, no Tocantins. O estudo procurou entender e explanar o que motivou o encurtamento da cadeia produtiva do arroz observado neste município. Trata-se de uma pesquisa de abordagem qualitativa de caráter exploratório e descritivo. A coleta dos dados foi realizada por meio de entrevista semiestruturada com partes interessadas da cadeia produtiva (produtores, agroindústria, fornecedores de insumos e máquinas, e poder público municipal). Alguns fatores contribuíram para a tomada de decisão do encurtamento como: condições climáticas e de solo favoráveis para a produção do arroz irrigado; redução dos custos logísticos e de produção. Os produtores foram beneficiados pela garantia de venda de seus produtos na colheita; melhora na classificação dos grãos refletido em ganhos financeiros; minimização de perecimento e má qualidade ocasionada pelo transporte; redução dos custos com secagem e armazenagem; confiança em investimento em tecnologia de ponta. Pode-se inferir o ganho nos aspectos econômicos e sociais para o município, incremento da arrecadação; crescimento no número de comércio; oferta de mão de obra na iniciativa privada; considerável aumento da população e a região tornando-se referência no cultivo de arroz irrigado.
\end{abstract}

Palavras-chave: Cadeias agro-alimentares. Cadeias curtas. Agronegócio.

\begin{abstract}
This study deals with the shortening process of a rice production chain, involving the beneficiation industry and the producers of the municipality of Lagoa da Confusão, in Tocantins. The study sought to understand and explain what motivated the shortening process observed in this municipality. The research is qualitative, exploratory and descriptive. Data collection was done through a semi-structured interview, with the actors of the production chain (producers, agroindustry, suppliers of inputs and machines, and municipality). Some characteristics contributed to the decision of shortening the chain such as: favorable climatic and soil conditions for irrigated rice production, associated to reduction of logistic and production cost. The producers benefited from the guarantee of sale of their products at harvest; improvement in grain classification reflected in financial gains; minimization of perishability and poor quality caused by transportation; reduction of drying and storage costs; investment in state-of-the-art technology. It can be inferred the gain in economic and social aspects for the municipality, increase of the collection; growth in trade numbers; supply of labor in the private sector; considerable increase of the population and the region becoming a reference in the cultivation of irrigated rice.
\end{abstract}

Keywords: Food supply chains. Shortened supply chains. Agribusiness.

Revista Produção Online. Florianópolis, SC, v. 20, n. 1, p. 95-118, 2020 


\section{INTRODUÇÃO}

O agronegócio movimenta a economia, gera riquezas e beneficia as cidades de seu entorno, melhorando substancialmente a vida de seus habitantes. No Brasil, o agronegócio do arroz ocupa lugar de destaque. A produção nacional de arroz em casca atingiu patamares de 12,2 milhões de toneladas durante o ano de 2014 (IBGE, 2014), ocupando o quinto lugar na produção nacional de grãos. O Brasil participa com aproximadamente $79,3 \%$ da produção total de arroz do Mercosul desde a safra 2008/09 até a 2014/15 (SOSBAI, 2014).

O Estado do Tocantins ocupou em 2015 a terceira posição no ranking da produção nacional de arroz, com uma produção de aproximadamente 604 mil toneladas do produto em casca, sendo o primeiro colocado na região norte (PLANETA ARROZ, 2015). Sua produção está em expansão, tanto em área como de produtividade (CONAB, 2014). O arroz produzido no Estado do Tocantins sob o sistema irrigado responde por aproximadamente $56 \%$ da produção da região Norte, com produtividade média de 4.767 quilos por hectare. O estado fica atrás apenas do Rio Grande do Sul e de Santa Catarina (CONAB, 2014; IBGE, 2014).

O município de Lagoa da Confusão se destaca entre os maiores produtores de arroz do Tocantins, tendo contribuído em 2012/2013 com 37,5\% da produção estadual. O município é o maior produtor estadual de arroz no sistema de cultivo irrigado, colhendo mais de 180.000 toneladas por ano (FRAGOSO et al., 2013) e sediando a instalação de um complexo agroindustrial local para o processamento e beneficiamento do cereal.

Cadeias produtivas como a do arroz podem variar em sua estrutura, o que possibilita modificá-la estrategicamente. Uma das possibilidades é o encurtamento da cadeia, que assim pode maximizar algumas vantagens dos atores envolvidos no processo, desde a produção até a comercialização de seus produtos (SELLITTO et al., 2018). Outra vantagem no encurtamento da cadeia é o aumento da eco eficiência do negócio, ou seja, manutenção ou até mesmo aumento da lucratividade com redução do impacto ambiental causado pelas atividades industriais (LUZ et al., 2006). Uma das principais causas geradoras de impacto ambiental em cadeias produtivas é o transporte e a consequente necessidade de estruturas de 
armazenagem mais complexas (SELLITTO et al., 2012). O impacto do transporte e da armazenagem pode ser reduzido com o encurtamento da cadeia.

De modo geral, em se tratando de arroz industrializado, empresas que encurtaram suas cadeias têm aumentado suas fatias de mercado (PARFITT et al., 2010). Esse movimento reflete na valorização de seus produtos, no desenvolvimento da localidade, além de gerar demanda de mão de obra, possibilitando melhorias reais para a região (LAGO et al., 2007). Atualmente, a indústria de beneficiamento do arroz vem seguindo uma tendência de encurtamento de sua cadeia produtiva, tendo como finalidade dinamizar sua produção e aumentar sua lucratividade. Essa reestruturação com base no encurtamento vem sendo observada no município de Lagoa da Confusão. O objetivo da indústria é aumentar sua competitividade pela aproximação entre seus elos, como observado por Vial (2010).

O objetivo deste artigo é identificar motivadores e implicações da decisão de encurtar a cadeia produtiva do arroz em Lagoa da Confusão, Tocantins. A principal técnica de pesquisa for a entrevista semiestruturadas com partes interessadas no processo de encurtamento da cadeia produtiva do arroz ocorrido no município da Lagoa da Confusão. As perguntas de pesquisa foram: (i) porque a cadeia foi encurtada? (ii) como a região foi afetada pelo encurtamento? O método de pesquisa é o estudo de caso. Os objetivos específicos estabelecidos foram: identificar os motivadores, identificar as implicações, e apontar conclusões e hipóteses para futuros estudos, mais aprofundados.

\section{REVISÃO}

A cadeia produtiva tradicional de arroz caracteriza-se por envolver em seu sistema de produção as etapas de produção, intermediação, secagem, armazenamento, indústria, distribuição e comércio. Paralelamente a estas atividades, a cadeia requer serviços, tais como sementes, insumos, assistência técnica, crédito, comercialização, etc. (MIRANDA et al., 2007). Já a cadeia encurtada é composta por três elos, nos quais o produtor negocia sua produção diretamente com a indústria que seca, armazena, beneficia, empacota e comercializa diretamente para o atacado, sem a presença do intermediário. Em cadeias 
encurtadas, além da redução de etapas (ficando a cargo da indústria a responsabilidade quanto à secagem, armazenamento e distribuição), ocorre uma aproximação geográfica entre a indústria de beneficiamento e o produtor local (SELLITTO et al., 2018). Na região de Lagoa da Confusão observam-se os dois tipos de estruturas de cadeias produtivas de arroz, como na Figura 1.

Figura 1- Estrutura da cadeia produtiva tradicional e encurtada

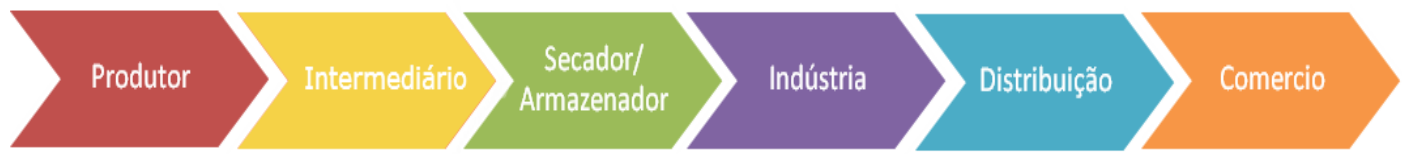

Cadeia tradicional da produção de arroz

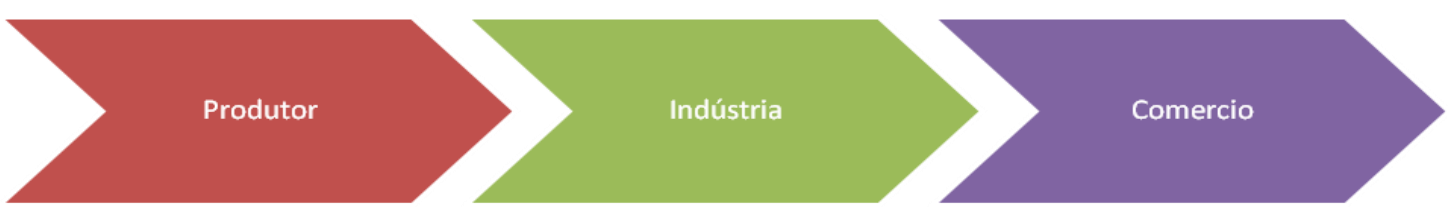

Cadeia encurtada da produção de arroz

Fonte: Adaptado de Vial (2010)

Em cadeias tradicionais, observam-se grandes distâncias geográficas entre o local de produção e a indústria de beneficiamento. A cadeia tradicional é composta por seis elos. Entre o produtor e a indústria, existe um elo intermediário responsável pela aquisição do arroz na propriedade, transportando-o para o elo seguinte, o secador e armazenador, que revende para a indústria. A indústria transforma o arroz em casca, empacota em fardos ou a granel, e envia para o elo de distribuição, composto geralmente por atacadistas e varejistas chegando por fim ao consumidor final.

A produção do arroz em casca requer o suporte de uma cadeia produtiva e de interligação entre seus elos, envolvendo negociações, aquisições, recursos financeiros e serviços, o que gera emprego e renda no entorno das regiões produtoras. Incluem-se na cadeia prestadores de serviço de assistência técnica (máquinas e equipamentos), venda de insumos, adubos, defensivos, seguros, serviços bancários, de sanidade, etc. A produção agrícola é influenciada por diversos fatores que interferem na produtividade, destacando-se a escolha da área, 
sistema de cultivo, qualidade das sementes, tecnologia de irrigação, e a época e a forma da semeadura (HOFF e BRUCH, 2007). Outro fator é o transporte de grãos entre a produção e o beneficiamento. Os esforços na elevação da produtividade podem ser comprometidos pela ineficiência do modal de transporte escolhido (SELLITTO et al., 2011). O transporte também é fator essencial para a eficiência da distribuição de produtos prontos (arroz polido, integral, parbolizado) e subprodutos reaproveitáveis gerados pela indústria (grãos quebrados, quirera, farelo e casca). Um caso excepcionalmente importante é o aproveitamento da casca de arroz como combustível na indústria cimenteira (SELLITTO et al., 2013). Por fim, o transporte é essencial para a eficiência da conexão entre o atacado e os pontos de consumo (VIEIRA et al., 2016).

No caso específico do Tocantins, há potencial de crescimento da cadeia do arroz em casca pelo fato de $30 \%$ da produção ser destinada a outros estados, e o arroz produzido localmente ser de boa qualidade. Não é vantajosa para as agroindústrias do estado a aquisição de arroz de outros estados, principalmente do Sul, devido o custo com o frete. Por esse motivo, o arroz tocantinense é negociado nos estados fronteiriços de Goiás e Bahia, o que se torna uma vantagem competitiva para a região (Fragoso et al., 2013).

Uma repercussão importante do cultivo do arroz na região é o aumento do PIB e da arrecadação dos municípios. O município de Lagoa da Confusão tem se destacado principalmente devido à expansão econômica produtiva da agroindústria arrozeira (IBGE, 2014). O PIB industrial do município multiplicou-se por seis entre 2009 e 2012, devido à instalação da agroindústria arrozeira, que começou a operar em 2010. A Figura 2 mostra a evolução da contribuição setorial da indústria ao PIB municipal no período. 
Figura 2 - Contribuição da indústria no PIB municipal (2009 - 2012)

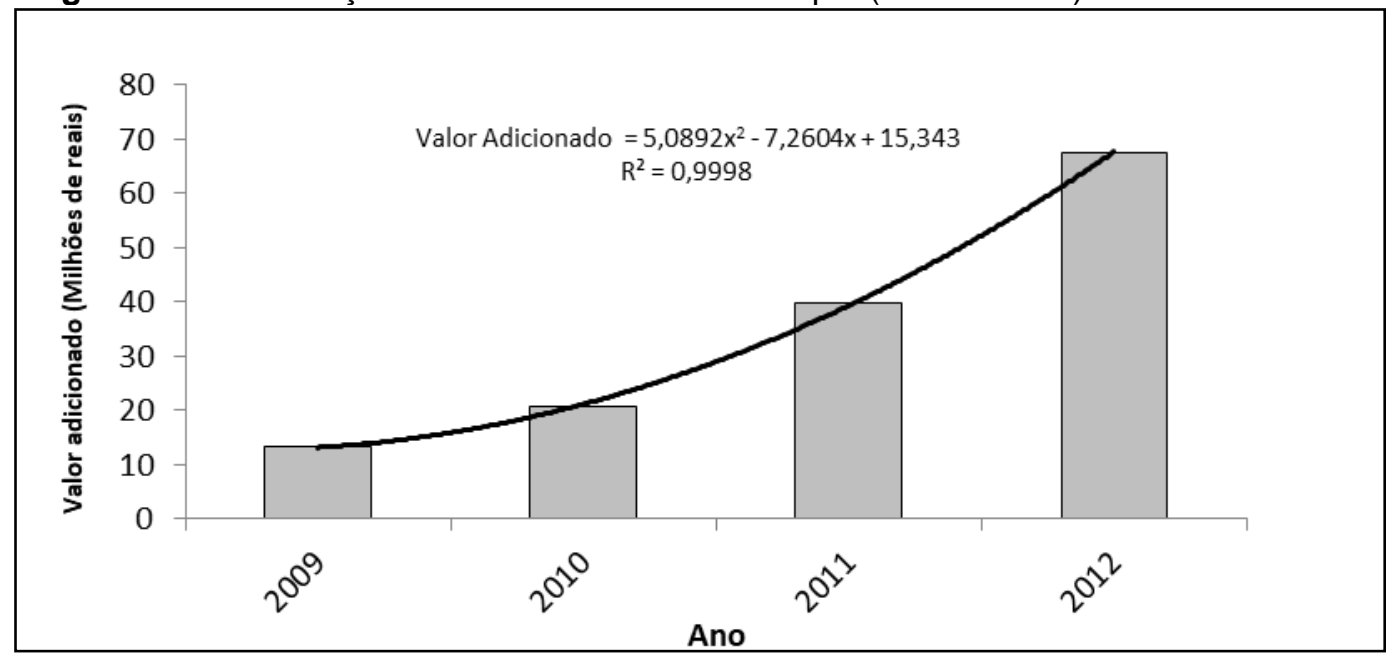

Fonte: IBGE (2013)

\section{MÉTODO DE PESQUISA}

A pesquisa é exploratória e descritiva e de caráter qualitativo. O método de pesquisa é o estudo de caso. É um delineamento qualitativo, pois investigar fatos, objetivos, atitudes e opiniões de atores, sem se valer de técnicas numéricas, estatísticas ou quantitativas para a análise (YIN, 2001). A principal técnica de pesquisa é a entrevista semiestruturada. $O$ objeto de pesquisa foi organizado conforme a revisão. Foram entrevistados os agentes envolvidos diretamente no encurtamento da cadeia representando as seguintes partes interessadas: produtores, agroindústria, apoio, e poder público. Para cada elo, foram selecionados aspectos destacados na revisão. Estes aspectos foram abordados em ao menos uma pergunta cada um.

Para produtores, foram nove perguntas relacionadas com a produção e tipificação do produto, forma de comercialização, preço, fatores limitantes da produção, uso de tecnologias, insumos, infraestrutura de apoio e escoamento da safra e a visão destes sobre a vinda da indústria para a região. Foram entrevistados dez produtores de arroz (E1 a E10) associados ao sindicato rural de Lagoa da Confusão. Este desequilíbrio (uma empresa industrial que se abastece de dez produtores de arroz) se explica pela própria estrutura produtiva da cadeia. Para a agroindústria foram seis perguntas relacionadas a características da indústria, preço de compra, distribuição, fornecedores, destino da casca de arroz e impactos do 
encurtamento da cadeia produtiva aplicadas ao gerente administrativo (E11) da única empresa da região, a CDA. Para o apoio, foram duas perguntas referentes ao encurtamento da cadeia, aplicadas a dois representantes dos setores de comércio de insumos, serviços e máquinas (E12 e E13). Para o poder público (Prefeitura Municipal) (E14) foi uma pergunta sobre as implicações do encurtamento para o município.

A análise dos dados qualitativos foi baseada na técnica de análise de conteúdo. Na pré-análise, redige-se e sintetiza-se o conteúdo das falas. Na análise, separa-se por categoria (partes interessadas). Por fim, comparam-se os discursos em busca de regularidades e convergências que possam gerar conclusões e hipóteses para futuras pesquisas.

\section{RESULTADOS DE PESQUISA E DISCUSSÃO}

Os resultados são apresentados e discutidos, separados por partes interessadas e quando necessário comparados com a literatura.

\subsection{Produtor}

Os produtores entrevistados trabalham na produção de arroz no município de Lagoa da Confusão, em média, há pelo menos 20 anos, variando entre 4 anos e 60 anos. Há produtores que vendem só para a CDA, que vendem para a CDA e para outros compradores, que vendem só para outros compradores, e um único produtor que beneficia sua produção vendendo diretamente ao atacado. A Figura 3 estratifica os entrevistados segundo o tipo de venda.

A maior parte dos produtores entrevistados $(80,0 \%)$ vende sua safra ao longo do ano. Somente $20 \%$ vende toda a safra de uma vez só. O fator que influencia esta decisão é a existência ou não de secador e armazenagem, conforme destacou o produtor E7: "a venda ocorre toda no momento da safra se o produtor não tiver secador e armazém". Essa falta de estrutura impacta diretamente na sustentabilidade econômica do setor, pois obriga muitos produtores a vender por baixo preço, dado o excesso de estoque. Sobre a precificação do arroz, as opiniões 
variam entre os produtores. Alguns comentaram que uma referência é o que acontece no Rio Grande do Sul, como relata o produtor E1: "O preço é determinado pela lei da oferta e procura. Baseamos nos preços do Rio Grande do Sul. A bolsa de valores não é parâmetro para nós. Quando há quebra no Rio Grande do Sul, o preço aqui aumenta muito". O preço em geral é variável de acordo com o mercado e o dia, mas existe a queixa entre os produtores sobre a existência de uma lógica de controle por parte das indústrias compradoras. Esta lógica não foi explicada e parece não ser bem compreendida pelos produtores. Segundo E1: "os produtores foram beneficiados com a CDA, pois deu estabilidade à comercialização". No entanto, muitos produtores ainda se queixam quanto à redução havida nos preços pagos pela indústria. A variação no preço do produto no momento da aquisição pela agroindústria foi detectada por Fragoso et al. (2013), que citam a incompreensão dos produtores com algumas variações nos preços pagos por seus produtos.

Figura 3 - Estratificação dos produtores segundo o tipo de venda

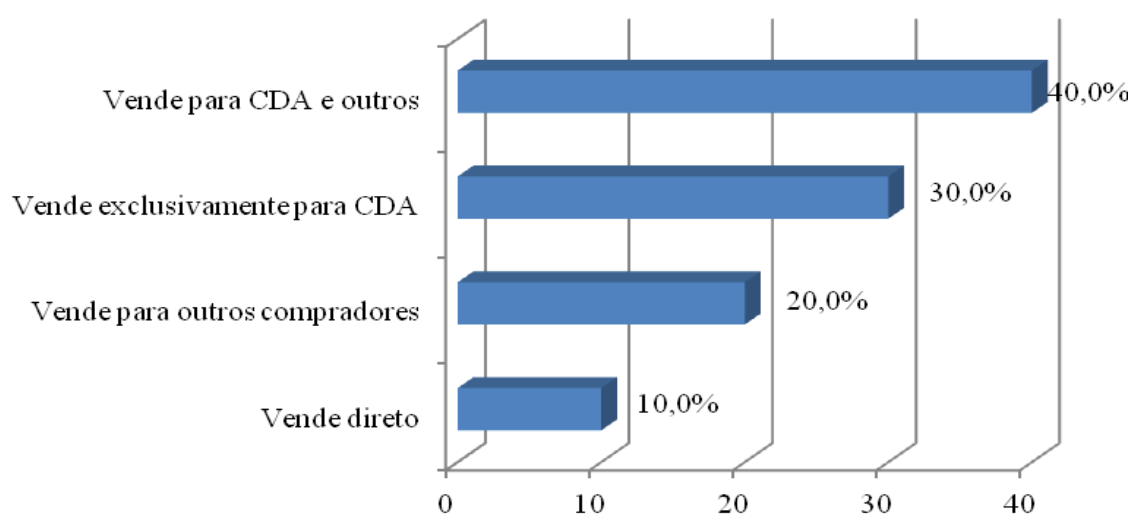

A Figura 4 apresenta o comportamento dos preços ao longo do ano. As oscilações correspondem ao período de safra e entressafra do arroz irrigado. $\mathrm{Na}$ safra, de abril a junho, a oferta é abundante e os preços caem. Na entressafra, o produto escasseia e o preço sobe. Os modelos de regressões não-lineares da figura, com elevados valores de $R^{2}$, confirmam o comportamento sazonal. 
Figura 4 - Preço do arroz entre 2013-2015

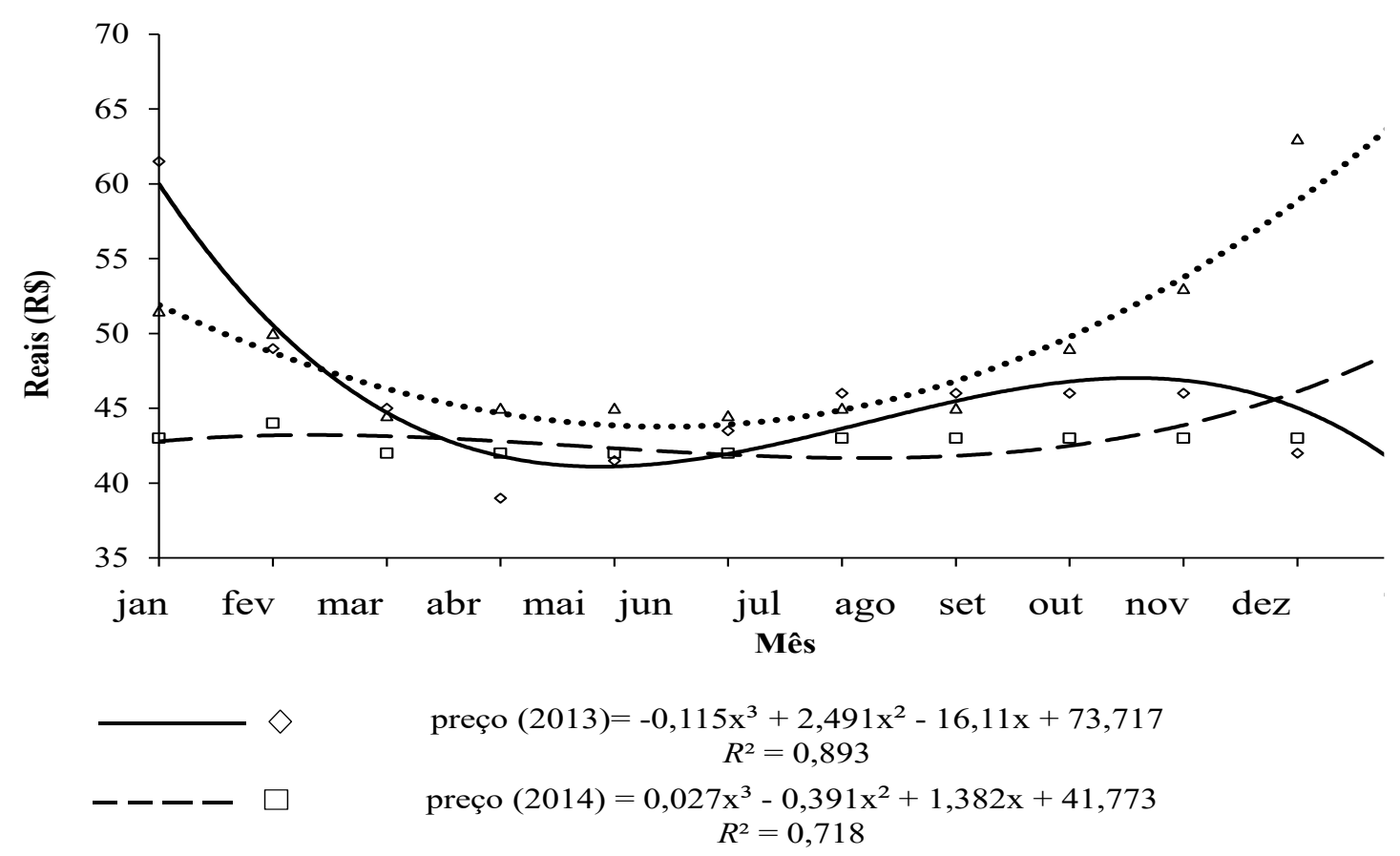

Fonte: Adaptado de SEAGRO (2016).

Quanto aos limitantes da produção, os produtores destacam doenças como a brusone como o maior problema, seguida de fatores climáticos (chuvas), dificuldades de aquisição de insumos e fertilizantes, política econômica e preço do dólar (influencia em alguns insumos), e legislação ambiental restritiva.

Quanto ao emprego de tecnologia na produção, os produtores destacaram as sementes de qualidade como fator de diferenciação e uso de maquinários de ponta, como comentou o produtor E4: "Boa semeadura só com sementes certificadas. O arroz requer muita oxigenação no período inicial. A sanidade é fundamental e tem que ser preventiva, para evitar a brusone". A regulagem da máquina colheitadeira e o controle efetivo da umidade ajudam a otimizar a colheita, mantendo a umidade entre 20 a 22\%. A secagem baixa a umidade nos grãos para 12 ou $11,7 \%$ antes de armazenar. O produtor E2 destacou a importância da assistência técnica: "tem que ter tecnologia de ponta, senão não tem lucro. As firmas que vendem insumos fornecem os agrônomos para acompanhar a produção e dão assistência técnica". A tecnologia investida influencia diretamente na produtividade e os cuidados são desde a escolha das sementes até a colheita, secagem e armazenamento do arroz. 
A regularidade nas vendas e uma certa valorização do produto aportada pela CDA ajudaram os produtores a ter fluxo de caixa e oferecer mais garantias para tomada de crédito. Com isto, muitos produtores equiparam-se com tecnologia, garantindo aumento na produtividade e lucros maiores para os produtores.

Quanto à estrutura de escoamento, os produtores destacam que não existe investimento por parte do poder público, as estradas se encontram em condições precárias e eles fazem benfeitorias por conta própria, pelo menos nas estradas mais próximas às fazendas. Não há melhorias significativas em estradas estaduais ou vicinais. E2 afirmou: "Muito ruim, estradas em péssimas condições e quando é preciso arrumar, o produtor arca com o óleo diesel das máquinas". E10 comentou que o poder público municipal até procura achar soluções, mas como são estradas estaduais tem sua ação restrita, o que dificulta o processo: "A prefeitura até tenta, mas não tem estrutura e a estrada é estadual. Não é por falta de vontade da prefeitura, mas não tem estrutura".

Quanto à estrutura de custos, os gastos com insumos representam de $60 \mathrm{a}$ $70 \%$ do custo da produção, segundo os entrevistados. Consideram que talvez isso poderia ser melhorado ou otimizado se a compra fosse realizada em conjunto, por cooperativa, mas essa iniciativa, embora tentada, não funcionou de forma adequada, conforme comentou o produtor E4: "O custo de aquisição gira em torno de $60 \%$ da produção, representando 5 sacos de semente, 18 sacos de adubo e 20 sacos de defensivos". A forma de aquisição é individual. Foi tentada compra conjunta pelo sindicato, mas a experiência não prosperou, pois há na região uma pluralidade cultural e isto foi decisivo para o insucesso. "Ficou uma imagem errada do cooperativismo". Vial et al. (2009) destacam a vantagem de organizar os produtores em torno de benefícios comuns, na aquisição conjunta dos insumos para a produção, e após a colheita, a associação na armazenagem e venda dos produtos em momentos oportunos. Essa associação traz benefícios, pois se conseguem melhores condições de negociação, os laços da cadeia produtiva são fortalecidos e se podem promover mudanças em políticas governamentais, em beneficio de todos e alavancar a competitividade do setor. A chegada da CDA não influenciou este aspecto. 
$\mathrm{Na}$ questão final, buscou-se compreender a visão do produtor sobre a vinda da CDA para a região e percebeu-se que as opiniões, embora sejam mais positivas que negativas, ainda são divergentes. Em torno de $70 \%$ dos produtores entrevistados consideram que a vinda da indústria foi boa, pois absorveu a produção, possibilitou aumento de escala de alguns produtores, criou estabilidade $\mathrm{e}$ é uma alternativa a mais na comercialização do produto. A aproximação da agroindústria propiciou um cenário atraente para instalação de outras empresas na região. Outras chegadas estimulariam a concorrência. $O$ fabricante do arroz Tio João conheceu a região e decidiu montar uma planta em Lagoa da Confusão. O projeto aguarda oferta de energia elétrica. Segundo E10, a concessionária está construindo uma linha de transmissão de $138 \mathrm{KV}$ para atender o município. Após a instalação, mais empresas poderão se instalar na região. E8 afirmou que o frete, que era pago pelo comprador, passou a ser pago pelo vendedor, o que representa um ônus antes inexistente para os produtores e devido unicamente à inexistência de mais opções de venda. Uma parcela dos produtores não considera positiva a vinda da CDA. Alegam que não existe preocupação por parte da empresa com o meio ambiente e a destinação das cascas do arroz, além de terem tido problemas com o pagamento da safra em alguns momentos, o que gera insegurança por parte dos produtores. Por essa razão consideram que seria positivo para o setor como um todo se outras empresas se instalassem na região, fortalecendo a cadeia produtiva.

\subsection{Agroindústria}

O grupo CDA (Companhia de Distribuição Araguaia) figura como uma das principais companhias de beneficiamento e distribuição de arroz do Brasil. A empresa tem um potencial produtivo de mais de 40 mil toneladas e atua nas regiões Centro-Norte e Nordeste do país. Possui uma unidade na cidade de Paraíso do Tocantins, desde 2002. A produção de arroz em casca no município não cresceu de modo significativo e o volume produzido não foi suficiente para abastecer o processamento e a produção da agroindústria. Com produção dispersa, era necessário recorrer a intermediários e a longos percursos por estradas em mau estado. Em 2010, a CDA decidiu concentrar aquisições de arroz em casca e 
construir uma unidade industrial no município de Lagoa da Confusão. Esta decisão foi motivada pela necessidade de concentrar a compra e de reduzir os custos com intermediários que prestavam serviços de secagem e armazenamento e com transporte de grãos até a agroindústria.

Para o gerente administrativo (E11), a concorrência na aquisição da matéria prima é um dos principais fatores que contribuíram na decisão de investir: "agora concentramos as compras em Lagoa da Confusão e no município vizinho Formoso do Araguaia". Os dois municípios têm histórico de vultosos embarques de arroz para outros estados. Dois aspectos relevantes foram identificados na entrevista com E11: a tomada de decisão da empresa em instalar-se no município e os benefícios econômicos e sociais desta decisão. O que motivou a tomada desta decisão foram as dificuldades encontradas para a consolidação da empresa em munícipio com pouca concentração de produtores. Os benefícios da decisão foram o aumento da lucratividade da operação e as repercussões sociais que se refletiram em mais e melhores salários pagos na região e em mais tributos para o poder público investir no município.

Tais reduções de custo são encontradas na literatura. Os custos logísticos em razão da dispersão geográfica entre produção, beneficiamento e consumo elevam os preços finais dos produtos. A redução desta logística influencia a competitividade da cadeia produtiva beneficiando todos os seus atores (OLIVEIRA, 2014). A dispersão da produção (agroindústria e produtor) não interessa ao beneficiamento. A concentração de atividades facilita as aquisições de matéria prima e de insumos e reduz custos de transporte (BECKMANN, 2011).

O deslocamento da agroindústria para áreas de maior disponibilidade de matéria prima ou de mais presença de consumidores é uma das principais estratégias para aumentar o poder de negociação, com sensível redução de custos de produção. Esse comportamento foi identificado por Miranda et al. (2007), ao estudar o sistema agroindustrial do arroz do Rio Grande do Sul. Outro fator considerado pela agroindústria é que o cultivo do arroz irrigado é menos suscetível a substituição do que outras culturas como, soja, milho, feijão e pastagens para a criação de gado, o que é corroborado pela literatura (WANDER e SILVA, 2014). 
A entrada da CDA foi influenciada pelo perfil produtivo da região que permite ao município produzir grande volume de cereais. Segundo levantamentos realizados pelo Instituto Brasileiro de Geografia e Estatística (IBGE) no ano agrícola de 2007, o município de Lagoa da Confusão produziu sozinho, 126 mil toneladas de arroz com casca, representando mais de $34 \%$ de toda a produção do Tocantins, seguido do município de Formoso do Araguaia, com quase 60 mil toneladas (IBGE, 2010). Nos anos agrícolas de 2012-2013, a produção no município teve relevante aumento, chegando a mais 182 mil toneladas (FRAGOSO et al., 2013), o que representa $18 \%$ de ganho em potencial produtivo.

A presença da empresa no município reforça um comportamento usual no meio agroindustrial, isto é, a migração de indústrias para locais de maior oferta de recursos. Naturalmente, a busca de maior competitividade e maior participação no mercado, repercute na entrada de empresas, traduzida pela procura de redução de custos de produção e de transporte, mão-de-obra de menor custo, incentivos financeiros dos governos. Esses fatores, segundo o Instituto de Pesquisa Econômica Aplicada - IPEA (2009), fazem com que as empresas estejam mais próximas de suas fontes de suprimentos de matérias-primas.

O investimento no encurtamento da cadeia suportado pela agroindústria teve respaldo na confiança depositada na classe produtora. Segundo E11: "houve interferência na produção, pois os produtores sentiram confiança e o nosso poder de compra ajudou". E11 destacou o tempo em que os produtores pesquisados trabalham na cultura do arroz irrigado no município: $60 \%$ dos produtores possuem mais de 25 anos e $40 \%$ entre 4 e 15 anos.

O encurtamento da cadeia com a interiorização da agroindústria esbarrou na dificuldade de encontrar mão-de-obra fabril qualificada para operar equipamentos baseados em tecnologias avançadas. Foi necessário treinamento as habilidades exigidas, o que é corroborado por Guedes et al. (2014). Segundo E11, um fator que impactou negativamente foi a mão de obra. Tivemos que capacitar e estamos capacitando até hoje. Na época da safra, é difícil manter pessoal com carteira assinada, pois o trabalho informal remunera melhor. O prefeito municipal, subsidiado por estudo sobre a influência do agronegócio no município, obteve do MEC a instalação de um campus avançado do Instituto Federal do Tocantins (IFTO), que 
desde 2014 oferece cursos técnicos em Informática e Agricultura. A implantação foi um marco histórico na relação entre a agroindústria e o município.

A chegada da agroindústria e o encurtamento de cadeia repercutiram na economia local. Sabe-se que o arroz colhido apresenta alto índice de umidade e impurezas, não sendo possível a armazenagem antes da secagem e retirada das impurezas. E11 destaca que melhorou a estrutura de secagem, na safra, e armazenamento, durante o ano, disponibilizada para os produtores. Tal melhoria estrutural implicou mais vendas ao longo do ano, o que elevou o preço médio do arroz em casca. Vendas concentradas na safra tendem a baixar o preço médio, por excesso de oferta. Tal observação encontra respaldo em Lima et al. (2013), que concluíram que a ausência de estrutura de secagem e armazenamento causa perdas de propriedades físicas e químicas, além da perda de valor comercial na cadeia da soja.

Com relação ao transporte, E11 afirma que houve melhoria substancial, pois deixou de ser feito em casca e a granel, passando a ser feito em fardos. Quanto aos fretes, antes eram FOB (sem ônus para o produtor), agora são CIF (com ônus para o produtor). Apesar de E11 apontar a mudança como vantajosa, um dos produtores a apontou como desvantajosa, e decorrente da concentração das vendas em um único comprador, o que foi uma importante implicação do encurtamento da cadeia.

Antes, o escoamento dos grãos da lavoura à agroindústria ocorria por rodovias estaduais não pavimentadas. Com o encurtamento da cadeia, muitos problemas de controle e de informação foram resolvidos ou ao menos reduzidos, com importante aumento no resultado geral do sistema local de produção. Tal observação confirma a pesquisa de Sellitto et al. (2011), que afirmam que a redução no sistema logístico requerido por uma cadeia produtiva elimina requisitos problemáticos, tais como pontos de estocagem, operações de transbordo ou operações multimodais, o que favorece a produção industrial. Antes, o transporte demorado elevava o tempo efetivo de transporte. Em consequência desse atraso, havia riscos de perdas de parte do arroz transportado, perda essa em função de intempéries climáticas (principalmente umidade e temperatura). De acordo com o SENAI (2015), o aumento da umidade associado a temperaturas inadequadas, favorece o aparecimento de fungos e aumenta os índices de perda de qualidade dos 
grãos. Com a redução do tempo de transporte, tanto a agroindústria como os produtores foram beneficiados.

Os preços finais não foram afetados pela aproximação da agroindústria, a chamada transmissão vertical, a distribuição na valorização do produto em igualdade entre os diversos elos da cadeia produtiva. Este desequilíbrio na distribuição de ganhos foi relatado por Santiago e Wander (2011) na cadeia do arroz em Goiás, em que a agroindústria não repassa para o varejo a queda do preço pago ao produtor. Vial (2010) também avaliou o comportamento do preço por unidade de produção da cadeia produtiva, neste caso, do leite bovino. O autor constatou que o preço do litro de leite após o encurtamento da cadeia produtiva permaneceu inalterado para o consumidor final, embora tenha sido economicamente vantajoso para produtor e indústria. Quanto à comercialização do arroz entre produtor e indústria, houve desfragmentação e maior direcionamento do objeto de compra. Em síntese, o volume produzido é ofertado a um número menor de empresas. Em torno de 40 a $60 \%$ é vendido para a CDA, a SLC e a Girassol absorvem 30 e 10\%, respectivamente, e uma pequena parcela é vendida diretamente ao atacado.

A agroindústria destaca erros que os produtores fazem ao avaliarem os preços pagos pela agroindústria. A maioria dos produtores se referem a preços praticados no Rio Grande do Sul, porém (1) no RS a saca é de 50 kg e no Tocantins é de $60 \mathrm{~kg}$, (2) no RS as distâncias são maiores e as estradas melhores, (3) as estruturas de salários de transportadores e tributárias são diferentes nos dois estados. Esse comportamento caracteriza a chamada transmissão horizontal dos preços estudada por Adami e Miranda (2011), que destacam a relação de influência dos preços do arroz no RS na formação dos preços do arroz no Mato Grosso.

E11 pontua que o produtor investiu e continua a investir na qualidade: "de cinco anos para cá a qualidade do produto de Lagoa da Confusão melhorou muito. Hoje pode ser comparada à do RS”. E11 reforça afirmações de produtores quanto à escolha do cultivar: "plantamos IRGA 424, a produtividade é alta e mais tolerante à Brusone" (E3), "a doença ataca o arroz e compromete a produtividade" (E10). "A ausência de pesquisa sobre a brusone compromete a produtividade. Há dez anos fazíamos duas aplicações de defensivos, agora são seis aplicações por safra" (E6). Dados coincidentes foram encontrados por Fragoso et al. (2013) em pesquisa que 
abrangeu todo o Tocantins. Cerca de $70 \%$ dos produtores plantavam IRGA 424 na área irrigada de arroz por ter boa produtividade e ser resistente à brusone. Outro fator citado por E11 que pode melhorar a produtividade é o desenvolvimento de material genético para o clima e solo da região. A EMBRAPA desenvolve material de forma incipiente, como constatado por Fragoso et al. (2013), que afirmam que os materiais da Embrapa apresentam bons resultados nos primeiros anos, mas inconsistentes no longo prazo.

Segundo E11, a agroindústria aloca esforços para dar destinação correta ao resíduo da casca do arroz originado do processo de secagem e industrialização. Desta, 20\% tem uso interno na fornalha de secagem, o que, além de retirar do meio ambiente o resíduo, contribui com a redução do desmatamento para produção de lenha. O restante não tem destinação final na agroindústria. Está em andamento uma negociação com fábrica de cimento, porém a distância excessiva (cerca de 700 $\mathrm{km}$ ) atravanca o processo. A empresa quer que a agroindústria arque com o custo, para dar destino ao resíduo. Está em estudo aproveitamento de retorno de carga, para que exista viabilidade econômica nesta operação. Sellitto et al. (2013), avaliando o coprocessamento de cascas de arroz e pneus inservíveis e logística reversa na fabricação de cimento, descrevem que para solucionar o problema da distância entre o beneficiamento e a empresa cimenteira, foi modificada a logística de abastecimento e foi criada uma central de consolidação de cargas (CCC), reduzindo, em média, 31,7\% no custo, justificando o investimento. Outra viabilidade para o coprocessamento da casca de arroz é a fabricação de briquetes, usados para queima em alto forno e em alguns casos substituir o carvão vegetal. Neste caso, o mercado tocantinense é pequeno para absorver toda a matéria prima disponibilizada pelas beneficiadoras, ressalta E11.

\subsection{Apoio: Insumo e Serviços}

O apoio representa o maior custo de produção do arroz irrigado. Esses custos são variados e dependem do mercado financeiro no momento da aquisição, pois fertilizantes, corretivos e defensivos normalmente são negociados em dólar. O município se destaca por possuir diversas empresas de insumos e serviços, 
negociando com os diversos segmentos da agricultura, pois além do arroz irrigado, também se destacam outras culturas como milho, soja e melancia, sendo que nesta última, o município é destaque no cenário nacional.

No apoio estão contemplados os fornecedores de insumos, serviços e máquinas. O consultor comercial da empresa que revende adubos e produtos químicos: herbicidas, fungicidas e inseticidas. Essas, além de revender os produtos, agregam o serviço de assistência técnica aliada à comercialização dos insumos. Em outras palavras, essas empresas dão a assistência técnica aos produtores sem custo adicional, quanto à formulação, utilização desses produtos e acompanhamento em sua aplicação. $O$ entrevistado colocou que, em muitos casos, os produtores, em torno de $20 \%$, não seguem a recomendação dos técnicos, "uns aplicam pouco, outros aplicam muito acima do recomendado". (E12).

Em relação a vinda da CDA para o município de Lagoa da Confusão foi positiva, por ter trazido mais secadores e armazenadores para a região. Existe uma proposta de trabalho que a empresa está desenvolvendo com os produtores para financiar o custo com os insumos, pois o crédito direto nos bancos onera o produtor. A CDA trouxe uma nova ferramenta para financiar o produtor que é a troca-troca: o produtor cota com a revenda de insumos e, de posse da cotação, procura a CDA para financiar os produtos. Neste caso, a CDA trabalha como trading, ou seja, fixa um valor futuro do preço da saca de arroz e o compromisso de entregá-los após a colheita. A CDA emite uma nota promissória que é entregue ao fornecedor de insumos e fica como avalista da operação. "Os títulos vencem antes da colheita. Caso o produtor não honre o compromisso, a justiça autoriza o confisco do arroz armazenado" (E12). O troca-troca representa um mecanismo alternativo para o produtor fugir dos altos juros cobrados pelo mercado financeiro, em decorrência do recuo na capacidade de financiamento pelos órgãos fomentadores da atividade agrícola.

Também se conversou com o fornecedor de máquinas e equipamentos agrícolas que responde pela gerência da unidade da empresa em Lagoa da Confusão. Segundo E13, o fornecedor comercializa e entrega os equipamentos, faz a revisão, atende no campo e com a estrutura na loja, atendem o pós-venda. Ele considera que quanto mais empresas vierem, melhor será para os negócios, com 
aumento de vendas, de produção e de máquinas. Comentou que desde 2013, devido à crise, o crédito foi reduzido aos produtores e o preço de produção teve um aumento de mais de $30 \%$. O que salvou os produtores foi a melhora no preço, em consequência da quebra de safra do arroz no Rio Grande do Sul, "a safra deste ano está com valores melhores, nunca vimos o arroz ser tão valorizado na colheita" (E13).

Devido à valorização nos preços, os produtores estão conseguindo saldar seus financiamentos e honrado os compromissos de forma antecipada, esse é um bom sinal, pois o banco reabre o crédito. No ano passado os juros estavam em 4,5\% ao ano para investimento, neste ano, está em $7,5 \%$ ao ano. Apontou que essa dificuldade de crédito está travando o comércio de máquinas, devido ao fato de os bancos e os produtores estarem cautelosos. A estiagem para o plantio também está trazendo incerteza aos produtores. Segundo o gerente, eles "necessitam da máquina, mas estão esperando o cenário melhorar" (E13).

Os entrevistados, de forma geral, consideram positiva a vinda da empresa e o encurtamento da cadeia, observam que trouxe melhorias, pois os produtores têm mais apoio. No entanto, ambos apontam a necessidade de mais investimentos, a chegada de mais beneficiadores, e ações conjuntas para alavancar o potencial produtivo do município.

\subsection{Poder Público Municipal}

Foi entrevistado o prefeito municipal (E14), que também é produtor. Segundo E14, a concentração da produção e do beneficiamento no município fez com que a região se desenvolvesse. O desenvolvimento econômico induziu o aparecimento de outras empresas, fornecedoras de insumos e de logística, gerando renda à população e fortalecendo o comércio. O desenvolvimento industrial da região trouxe para o município empreendimentos em diferentes áreas de atuações, favorecendo a sociedade e o crescimento do município, como relatado pelo prefeito: "Vieram retíficas de motores, autopeças, representantes de máquinas agrícolas, fertilizantes, defensivos e aumentou a ocupação dos hotéis da cidade" (E14). Houve expressivo aumento na arrecadação de tributos associados à prestação de serviços, o ISS. 
Outro setor que acompanhou o desenvolvimento da agricultura foram as instituições bancárias, que financiam as lavouras e maquinários utilizados na produção.

A agregação de valor ao produto tornou a região referência na produção de arroz irrigado, trouxe garantia de comercialização dos produtos, e aumentou a oferta secagem e armazenagem. A agregação de influencia positivamente no cálculo do índice do valor adicionado, quotas-partes, referente à parcela do IPM (índice de participação dos municípios), que é aplicado sobre o montante da arrecadação do ICMS estadual. Desta arrecadação são distribuídos $25 \%$ para o município e $75 \%$ para o estado (SEFAZ, 2015).

Por outro lado, a agregação de valor aumentou a população do munícipio, pois atraiu empregados e empreendedores, o que acarretou aumento na oferta de serviços públicos municipais (saúde, saneamento, educação). No entanto, E14 reforçou que os aumentos de arrecadação e de serviços necessários não foram equivalentes: houve mais aumento de arrecadação do que de demandas, o que configurou um quadro final positivo. E14 encontra duas explicações para tanto. A primeira é que o aumento de população se deveu à chegada de públicos com renda, seja de empregados, seja de empreendedores, o que pouco onerou os serviços gratuitos do município. A segunda é que muitos novos empreendimentos da cidade passaram a fazer negócios com entidades fora da região, o que aportou recursos gerados em outras localidades, aumentando a massa de recursos circulantes na região. Esta massa nova financiou, com sobras, o aumento de serviços prestados pelo poder público.

\subsection{Análise Conjunta}

Para encerrar a discussão, é de interesse oferecer um olhar sinótico sobre as falas dos entrevistados. Para tanto, os principais trechos das entrevistas foram destacados. Os destaques foram classificados em motivações (ou antecedentes), fatores que aconteceram antes da decisão de encurtar a cadeia) e implicações (ou consequentes), elementos que surgiram depois da decisão. O Quadro 1 sintetiza esta visão sinótica dos achados. 
Quadro 1 - Síntese das conclusões do estudo

\begin{tabular}{|c|c|c|c|c|c|c|}
\hline \multirow[b]{2}{*}{ Elemento de fala } & \multicolumn{4}{|c|}{ Presente no discurso de } & \multicolumn{2}{|c|}{ Fator } \\
\hline & Produtores & Agroindústria & Apoio & $\begin{array}{l}\text { Poder } \\
\text { Público }\end{array}$ & Antecedente & Consequente \\
\hline Redução da concorrência na hora da compra & $\mathrm{X}$ & $\mathrm{X}$ & & & $\mathrm{X}$ & \\
\hline Redução de custos de produção na indústria & & $\mathrm{X}$ & & & $\mathrm{X}$ & \\
\hline Alta concentração de produtores na região & & $\mathrm{X}$ & & & $\mathrm{X}$ & \\
\hline $\begin{array}{r}\text { Mais estabilidade nas vendas e melhores preços ao longo } \\
\text { do ano }\end{array}$ & $\mathrm{X}$ & $X$ & & & & $X$ \\
\hline Mais tecnologia na produção & $\mathrm{X}$ & $\mathrm{X}$ & $\mathrm{X}$ & $\mathrm{X}$ & & $\mathrm{X}$ \\
\hline Redução nas dificuldades logísticas & $\mathrm{X}$ & $\mathrm{X}$ & & $\mathrm{X}$ & & $\mathrm{X}$ \\
\hline Melhoria na infra-estrutura geral da região & $\mathrm{X}$ & & & $\mathrm{X}$ & & \\
\hline Melhoria e qualificação da mão-de-obra local & & $\mathrm{X}$ & $\mathrm{X}$ & & & $\mathrm{X}$ \\
\hline Melhoria da qualidade do produto local & & $\mathrm{X}$ & $\mathrm{X}$ & $\mathrm{X}$ & & $\mathrm{X}$ \\
\hline Aumento na oferta e na qualidade do crédito & & & $\mathrm{X}$ & & & $\mathrm{X}$ \\
\hline $\begin{array}{r}\text { Mais e melhores salários, mais arrecadação, diversificação } \\
\text { de negócios e agregação de valor }\end{array}$ & & $\mathrm{X}$ & $\mathrm{X}$ & $\mathrm{X}$ & & $\mathrm{X}$ \\
\hline
\end{tabular}

Fonte: Elaborado pelos autores 


\section{CONCLUSÕES}

O estudo propiciou conclusões que serão apresentadas sob a forma de hipóteses para estudos futuros. As hipóteses foram divididas em motivadores $\left(H_{1 x}\right)$, que aconteceram antes e podem ter justificado a decisão de encurtamento da cadeia e implicações $\left(H_{2 x}\right)$, que vieram depois e podem ter sido causadas pelo encurtamento da cadeia. As conclusões e hipóteses são:

- $H_{11}$ : Uma região com baixa concentração de produção primária tende a ser menos atraente para a atividade agroindustrial;

- H12: Uma região com alta concentração de produção primária tende a ser mais atraente para a atividade agroindustrial;

- H13: Excesso de intermediários, longas distâncias e dificuldades na cadeia produtiva agrícola motivam o encurtamento da cadeia pela aproximação da agroindústria com a produção;

- $H_{21}$ : Encurtamento na cadeia produtiva acarreta mais estabilidade nas vendas e melhores preço ao longo do ano;

- $H_{22}$ : Encurtamento na cadeia produtiva acarreta mais tecnologia na produção;

- H23: Encurtamento na cadeia produtiva acarreta redução nas dificuldades logísticas;

- $H_{24}$ : Encurtamento na cadeia produtiva acarreta melhoria na infraestrutura geral da região;

- $H_{25}$ : Encurtamento na cadeia produtiva acarreta melhoria e qualificação da mão-de-obra local;

- $H_{26}$ : Encurtamento na cadeia produtiva acarreta melhoria qualidade do produto local;

- $H_{27}$ : Encurtamento na cadeia produtiva acarreta aumento na oferta e na qualidade do crédito;

- H28: Encurtamento na cadeia produtiva acarreta Mais e melhores salários, mais arrecadação, diversificação de negócios e agregação de valor. 
Como sugestão para futuras pesquisas, apontam-se dois tipos de estudo: estudos de caso em profundidade, no qual uma ou poucas das conclusões deste estudo serão testadas em profundidade; e um survey em uma cadeia produtiva inteira que tenha sido encurtada, para verificação, por métodos estatísticos multivariados, das hipóteses de pesquisa.

\section{RECONHECIMENTOS}

Parte da pesquisa foi financiada pelo CNPq.

\section{REFERÊNCIAS}

ADAMI, A.; MIRANDA, S. Transmissão de preços e cointegração no mercado brasileiro de arroz. Revista de Economia e Sociologia Rural, v. 49, n. 1, p. 55-80, 2011. https://doi.org/10.1590/S0103-20032011000100003

BECKMANN, E. Estudo da cadeia produtiva do arroz de mato grosso: impactos do setor de beneficiamento na economia regional em 2011. (Dissertação de Mestrado). Universidade Federal de Mato Grosso. Mestrado em Agronegócios e Desenvolvimento Regional, 2011.

CONAB. Companhia Nacional de Abastecimento. Indicadores da Agropecuária.

Companhia Nacional de Abastecimento. Ano XXII, Brasília: Conab, (11), p. 01-92, 2014.

IBGE. Instituto Brasileiro de Geografia e Estatística. Dados estatísticos: Estados do Tocantins. 2013. Disponível em: http://www.ibge.gov.br/. Acesso em: 10 fev. 2015.

IBGE. Instituto Brasileiro de Geografia e Estatística. Levantamento Sistemático da produção Agrícola: pesquisa mensal de previsão e acompanhamento das safras agrícolas no ano civil. Fundação Instituto Brasileiro de Geografia e Estatística, 2014. Disponível em: http://www.ibge.gov.br/. Acesso em: 10 fev. 2015.

FRAGOSO, D. B.; CARDOSO, E. A.; SOUZA, E. R.; FERREIRA, C. M. Caracterização e diagnóstico da cadeia produtiva do arroz no estado do Tocantins. Brasília - DF, EMBRAPA, 2013.

GUEDES, A. C.; TORRES, D. A. P.; CAMPOS. S. K. Sustentabilidade e sustentação da produção de alimentos e o papel do Brasil no contexto global: Tendências recentes. In: BUAINAIN, A. M.; ALVES, E.; SILVEIRA, J. M.; NAVARRO, Z. (Org). O mundo Rural no Brasil do Século 21. Brasília: Embrapa, p. 116-146, 2014.

HOFF, D.; BRUCH, K. Diferenças de finalidade e modificações estruturais na filière do arroz biodinâmico: o caso de Sentinela do SuL, RS. Organizações Rurais \& Agroindustriais, v. 9, n. 3, p. 362-375, 2007. 
IPEA. Instituto de Pesquisa Econômica Aplicada. 2009. Indústria - Fuga da capital Expansão mostra interiorização das fábricas. Brasília-DF. Disponível em: http://goo.gl/bCf3uC. Acesso em: 08 dez. 2015.

LAGO, A.; CORONEL, D. A.; LENGLER, L.; SILVA, T. N.; OLIVEIRA, C. B. O setor orizícola brasileiro e gaúcho: desafios, oportunidades e estratégias frente à crise atual. Cadernos de Economia, Curso de Ciências Econômicas, Unochapecó, v. 11, n. 20, 2007.

LIMA, R. F. de; FAORO, V.; WINIK, V. S.; KHATCHATOURIAN, O. Armazenamento e Secagem de Grãos de Soja. In: JORNADA DE PESQUISA, 18., 2013. [Anais...]. ljuí, RS, 2013.

LUZ, S.; SELLITTO, M.; GOMES, L. Medição de desempenho ambiental baseada em método multicriterial de apoio à decisão: estudo de caso na indústria automotiva. Gestão \& Produção, v.13, n. 3, p. 557-570, 2006. https://doi.org/10.1590/S0104-530X2006000300016

MIRANDA, S.; SILVA, G.; MOTTA, M.; ESPOSITO, H. o sistema agroindustrial do arroz no Rio Grande do Sul. In: CONGRESSO DA SOBER, 45., 2007. [Anais...]. Londrina, 2007.

OLIVEIRA, A. A logística do agronegócio para além do "apagão logístico": Implicações para a política agrícola. In: BUAINAIN, A. M.; ALVES, E.; SILVEIRA, J. M.; NAVARRO, Z. (Org). O mundo rural no Brasil do século 21. Brasília: Embrapa, p. 237-369, 2014.

PARFITT, J.; BARTHEL, M.; MACNAUGHTON, S. Food waste within food supply chains: quantification and potential for change to 2050. Philosophical Transactions of the Royal Society B: Biological Sciences, v. 365, n. 1554, p. 3065-308, 2010. https://doi.org/10.1098/rstb.2010.0126

PLANETA ARROZ. 2015. Disponível em: http://www.planetaarroz.com.br/. Acesso em: 03 jan. 2016.

SANTIAGO, C. M.; WANDER, A. E. Análise de Distribuição de ganhos na cadeia produtiva do arroz no Estado de Goiás. In: CONGRESSO BRASILEIRO DE ARROZ IRRIGADO, Balneário Camboriú - SC. [Anais...]. Itajaí - SC: Epagri/Sosbai. 1, p. 761-763, 2011.

SELLITTO, M. A., KADEL JR, N., BORCHARDT, M., PEREIRA, G. M., DOMINGUES, J. Rice husk and scrap tires co-processing and reverse logistics in cement manufacturing. Ambiente \& Sociedade, v. 16, n. 1, p. 141-162, 2013. https://doi.org/10.1590/S1414-753X2013000100009

SELLITTO, M.; BORCHARDT, M.; PEREIRA, G.; GOMES, L. Environmental performance assessment of a provider of logistical services in an industrial supply chain. Theoretical Foundations of Chemical Engineering, v. 46, n. 6, p. 691-703, 2012. https://doi.org/10.1134/S0040579512060206

SELLITTO, M.; BORCHARDT, M.; PEREIRA, G.; PAULO, L. Environmental Performance Assessment in Transportation and Warehousing Operations by Means of Categorical. Chemical Engineering Transactions, n. 25, p. 291-296, 2011.

SELLITTO, M.; VIAL, L.; VIEGAS, C. Critical success factors in Short Food Supply Chains: Case studies with milk and dairy producers from Italy and Brazil. Journal of Cleaner Production, v. 170, p. 1361-1368, 2018. https://doi.org/10.1016/j.jclepro.2017.09.235 
SENAI. Serviço Nacional de Aprendizagem Industrial. Curso e treinamento em secagem e aeração de grãos armazenados. Palmas, 2015.

SOSBAI. Sociedade Sul- Brasileira de arroz irrigado. Recomendações Técnicas da Pesquisa para o Sul do Brasil. In: REUNIÃO TÉCNICA DA CULTURA DO ARROZ IRRIGADO, 30., 2014. Bento Gonçalves/RS, 2014.

TOCANTINS. Secretaria da Fazenda do Estado do Tocantins - SEFAZ. 2015. Conselho especial para elaboração do índice de participação dos municípios - CEIPM-ICMS. Palmas/TO. Disponível em: http://www.sefaz.to.gov.br/IPM/IPM 2007/ManuallPM2007.htm. Acesso em: 03 jan. 2016.

TOCANTINS. Secretaria de Agricultura e Pecuária do Governo do Estado do Tocantins SEAGRO. 2016. Cotações Agropecuárias 2016. Disponível em: http://goo.gl/oyF4PM. Acesso em: 14 jan. 2016.

VIAL, L. Encurtando distância entre produtores e consumidores: a abordagem da filiera corta para cadeias agroalimentares. (Dissertação de Mestrado). Programa de Pósgraduação em engenharia de produção e sistemas da Universidade do Vale do Rio dos Sinos, 2010.

VIAL, L; SETTE, T. C. C.; BATISTI, V. S.; SELLITTO, M. A. Arranjos produtivos locais e cadeias agro-alimentares: revisão conceitual. GEPROS. Gestão da Produção, Operações e Sistemas, v. 4, n. 3, p. 105-121, jul./set. 2009.

VIEIRA, J. G., CARVALHO, C. D., YOSHIZAKI, H. Y. Atributos da distribuição de carga e indicadores de desempenho logístico: pesquisa com empresas que atuam na região metropolitana de São Paulo. Transportes, v. 24, n. 4, p. 10-20, 2016. https://doi.org/10.14295/transportes.v24i4.912

WANDER, A. E.; SILVA, O. F. da. Rentabilidade da produção de arroz no Brasil. Embrapa Arroz e Feijão. CNPAF. p. 117-133, 2014. Disponível em:

http://www.alice.cnptia.embrapa.br/handle/doc/1016409. Acesso em: 16 jan. 2015.

YIN, R. Estudo de caso: planejamento e método. Porto Alegre: Bookman, 2001.

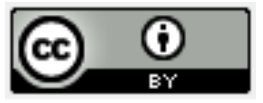

Artigo recebido em: 26/05/2018 e aceito para publicação em: 04/03/2020 DOI: http://dx.doi.org/10.14488/1676-1901.v20i1.3259 